\title{
Influence of caregiver on heart failure patients' disease beliefs and compliance
}

\author{
Sibel Sevinc ${ }^{* *}$ and Sevgin Samancioglu ${ }^{2}$ \\ ${ }^{1}$ Department of Nursing, School of Health, Kilis 7 Aralik University, Kilis, Turkey \\ ${ }^{2}$ Health Science Faculty, Gaziantep University, Gaziantep, Turkey
}

\begin{abstract}
Background: Adherence to treatment can effect cognitive conditions and medication and dietary compliance in HF patients. Caregiver burnout may affect a patient's disease adherence and beliefs.

Objective: This study was descriptive design and carry out to determine the relationship of caregiver burden with compliance and belief in HF patients.

Patients and methods: The study was performed at the University Hospital in the Province of Gaziantep, Turkey and comprised 92 heart failure patients who were hospitalized in cardiology clinics and their caregivers. In this study, a questionnaire regard socio-demographic data and disease, the Beliefs about Medication Compliance Scale, the Beliefs about Dietary Compliance Scale, the Beliefs about Self-Monitoring Scale and The Zarit Burden Interview were used to collect data.

Results: There were significant differences in the burden of the caregiver for different lengths of caregiving duration ( $\mathrm{r}=0.265$, $\mathrm{P}=0.011$ ). It was determined that the patients of caregivers with a high level of burden had higher perceived benefits of medication and dietary compliance and self-monitoring while their perceived barriers to medication compliance were low.
\end{abstract}

Conclusion: It could be argued that the higher the burden of caregivers, the higher the disease compliance of patients.

\section{Background}

The prevalence of heart failure (HF) is higher in Turkey than in western countries, even though Turkey has a younger population [1]. $\mathrm{HF}$ is a complicated clinical syndrome and it result from any structural or functional impairment of ventricular filling or ejection of blood [2]. Therefore, people suffer from heart failure must re-organize their lifestyles on eating, medication recall, close attention to their body and stress reduction. These lifestyle modifications require the patient to comply with and believe medication, diet and self-monitor. A caregiver may help them in disease process. But, HF patients' caregivers may need to be strength for a long time [3]. These people may experience burnout while caring for their patients. Caregiver burnout may affect a patient's disease compliance and beliefs.

Several studies have shown that caregivers experience many challenges and burnout during the HF patient caring process [4-7]. It has been described by many studies that the adherence to treatment can effect cognitive conditions and medication and dietary compliance in HF patients $[8,9]$. However, no study has been conducted with HF patients regarding the effect of caregiver burden on a patient's disease compliance and beliefs [8-11].

Identifying the relationship of caregiver burden with compliance and belief in HF patients will contribute to family based caring interventions; it could further contribute to better HF outcomes and improvements in management practices by health care providers and nurses.

\section{Objectives}

The study aim was to determine the relationships of caregiver burden with compliance and beliefs in patients with heart failure.

\section{Materials and methods}

This study was conducted at the University Hospital in the Province of Gaziantep, Turkey. It was descriptive and cross-sectional design. The study sample consisted patients with HF and their caregiver in cardiology clinic. The patients and caregivers who were volunteers and were available during data collection were selected. The study sample consisted of 92 HF patients hospitalized in cardiology clinics and their caregivers. The inclusion criteria for patients were as follows: (a) they had HF at least in the past six months and (b) they had NYHA (New York Heart Association) II-IV. The inclusion criterion for caregivers was as follows: (a) they had been caregivers at least in the past six months. Other inclusion criteria for HF and caregivers were as follows: aged 18 years or older, not having mental, physical or psychiatric illness, not having problems with hearing, eyesight and speech.

\section{Questions of Research}

1. What are the HF patient characteristics that affect their beliefs about medication compliance, dietary compliance, and selfmonitoring?

Correspondence to: Sibel Sevinc, PhD, RN, Assistant Professor, Department of Nursing, School of Health, Kilis 7 Aralik University, Kilis, Turkey, E-mail: sibelsevis@gmail.com

Key words: disease beliefs and compliance, burnout of caregiver, heart failure

Received: March 31, 2017; Accepted: April 14, 2017; Published: April 17, 2017 
2. What are the caregiver characteristics that affect caregiver burden?

3. What are the relationships between the level of beliefs about medication compliance, dietary compliance, and self- monitoring in HF patients and caregiver burden?

\section{Ethical considerations}

The Institutional Ethics Committee of Gaziantep University Medical Faculty (07.01.2014/12) approved this study before implementation. All of the patients and their caregivers gave verbal and written informed consent.

\section{Data collections tools}

The tools were a questionnaire form about socio-demographic data and disease, the Beliefs about Medication Compliance Scale (BMCS), the Beliefs about Dietary Compliance Scale (BDCS), the Beliefs about Self-Monitoring Scale (BSMCS) and the Zarit Burden Interview (ZBI).

Descriptive questionnaire: The patient questionnaire consisted of questions about patients' socio-demographic and disease data, and caregiver questionnaire consisted of questions regarding caregivers' socio-demographic characteristics. The researchers administered the questionnaire. The questionnaire forms were administered to each patient and caregiver while they were alone.

Beliefs about medication compliance scale: The Beliefs about Medication Compliance Scale (BMCS) was developed by Bennett et al. [12]. The BMCS has a 12-item questionnaire and a 5-point response scale (ranging "strongly disagree" - "strongly agree") that is designed to measure the perceived benefits of and barriers to medication compliance in persons suffer from HF. Since the patients with HF reported that the side effects of diuretic treatment affected their daily living activities, these measures were focused on compliance with diuretic treatment. The five of items measures the benefits of drug compliance; the remaining 7 items measure barriers to medication compliance. A benefit score and a barriers score for the respective scales are obtained by summing the responses to these items [13]. The internal consistencies of the benefits and barriers scales, as estimated by Cronbach's $\alpha$, were 0.87 and 0.91 , respectively. Item 9 on the scale is reverse coded. A study carried out by Oguz et al. [14] tested the reliability of the Turkish version of the BMCS the Cronbach's alpha internal consistency coefficients were 0.90 and 0.91 for the benefits and barriers scales, respectively. The Cronbach's alpha internal consistencies for the benefits and barriers scales were 0.85 and 0.70 , respectively in this study.

Beliefs about dietary compliance scale: The Beliefs about Dietary Compliance Scale (BDCS) was developed by Bennett [12]. The BDCS has a 12-item questionnaire and a 5-point scale (ranging "strongly disagree" - "strongly agree"). These items measure the perceived benefits of and barriers to compliance with dietary sodium restrictions in persons suffer from HF. Seven of the items measure the benefits of compliance and 5 items measure the barriers to compliance about sodium restrictions. A benefits score and a barriers score are obtained by summing the responses to the items for each scale. The internal consistencies of the benefits and the barriers scales were satisfactory in 101 patients with HF. The internal consistencies, as estimated using Cronbach's a statistic, were 0.84 and 0.68 , respectively. Item 2 on the scale is reverse coded. A study carried out by Oguz et al. [14] tested the reliability of the Turkish version of the BDCS; the Cronbach's alpha internal consistency coefficients were 0.86 and 0.86 for the benefits and barriers scales, respectively. Cronbach's alpha internal consistencies for the benefits and barriers scales were 0.70 and 0.69 in this study.

Beliefs about self-monitoring compliance scale: The Beliefs about Self-Monitoring Compliance Scale (BSMCS) was developed by Bennett et al. $[12,13]$. BSMCS, which was culturally adapted to Turkey [14], has 18 items with a five-point response scale ranging strongly disagreetotally agree. It is intended to measure the perceived benefits and barriers to behavior adherence regarding the daily self-monitoring of weight and edema. Six items measure the benefits to adherence, and 12 items measure the barriers to adherence. A total score for each subscale can be obtained from the instrument by adding the responses for each item. The score of the benefits subscale varies between 6 and 30, and the higher the score, the greater the perceived benefits. The score of the barriers subscale varies between 12 and 60, and the higher the score is, the higher the perceived barriers are.

In Oğuz's study, the internal consistency assessed by Cronbach's alpha was 0.90 for the benefits subscale and 0.93 for the barriers subscale [14]. Cronbach's alpha internal consistencies for the scales were 0.83 and 0.73 for the benefits and barriers scales, respectively in our study.

Zarit Burden Interview: The Zarit Burden Interview (ZBI) was developed by Zarit, Reever, and Bach-Peterson [15]. The ZBI contains 22 items with a 5-point Likert-type response scale (from never- 0 , to nearly always-4) and is used to assess caregiver burden. The total burden was obtained by adding the scores for all items, ranging from 0-88, where higher scores indicate greater burden [15]. A study carried out by İnci and Erdem [16] tested the validity of the Turkish version of the ZBI; the Cronbach's alpha internal consistency coefficient was 0.95 [16]. The alpha internal consistency for the scale was 0.89 in this study.

\section{Data analysis}

Statistical Package for the Social Sciences (SPSS, Version 15.0 for Windows) software was used for statistical data analysis. Univariate statistics were used to describe the subject characteristics and responses to the scales. To compare data, we used Student's t-test, analysis of variance, the Mann-Whitney U test, Kruskal-Wallis test and Pearson's correlation analysis. Scale reliability was analyzed using Cronbach's alpha internal consistency test, and the results were considered significant at $\mathrm{P} \leq 0.05$.

\section{Results}

The average age of the patients was $59.9 \mathrm{y}$ (SD $17.11 \mathrm{y}$, range: 18$92 \mathrm{y}$ ), and the average age of the caregivers was $47.5 \mathrm{y}$ (SD $14.77 \mathrm{y}$, range: $18-83$ y). Other descriptive data for the patients and caregivers are displayed in Table 1 . In some cases, the caregivers were related to the patients in some way; $25 \%(n=23)$ of caregivers were the patient's daughter, $5.4 \%(n=5)$ were the patient's daughter-in-law, $17.4 \%(n=16)$ were the patient's son, $47.8 \%(\mathrm{n}=44)$ were the patient's wife/husband, $3.3 \%(n=3)$ were a caregiver, and $1.1 \%(n=1)$ was another person. On average, the caregivers were caregivers for 5.59 (SD 4.41) years.

\section{BMCS, BDCS, and BSMCS scores}

Table 2 shows the average subscale scores for the BMCS, the BDCS, and the BSMCS. The patients' subscale scores did not differ significantly according to socio-demographic and disease characteristics, such as illness duration, ejection fraction (EF), gender, employment status, and education. However, there were significant differences in the BMCS benefit $(\mathrm{r}=0.289, \mathrm{P}=0.005)$, BMCS barrier $(\mathrm{r}=-0.342, \mathrm{P}=0.001)$ and BSMCS barrier subscales scores $(\mathrm{r}=-0.240, \mathrm{P}=0.021)$ between patients 
of different age groups. The BDCS benefit score was associated with the patient's marital status (Mann Whitney $\mathrm{U}=245.00, \mathrm{P}=0.015, \mathrm{Z}=$ 2.426); single patients had higher scores than married patients. The BSMCS benefit score was associated with the patient's NYHA (Kruskal Wallis=9.034, $\mathrm{P}=0.011$ ); patients with NYHA-IV had higher scores than those with other NYHA classes.

\section{Zarit Burden Interview scores}

The total average ZBI score for all caregivers was 40.90 (SD, 14.55) points (see Table 2). There was no significant difference in scores for socio-demographic and caregiving data, such as age $(\mathrm{r}=-0.106, \mathrm{P}=0.315)$, gender $(\mathrm{t}=0.252, \mathrm{P}=0.801)$, marital status $(\mathrm{U}=581.000, \mathrm{P}=0.781)$, level of education (Kruskal Wallis $=0.686, \mathrm{P}=0.710$ ), and employment status $(t=1.106, P=0.312)$. There were significant differences found in the caregiver burden (ZBI score) among those with different caregiving lengths $(\mathrm{r}=0.265, \mathrm{P}=0.011)$.

Table 1. Patients' ( $\mathrm{n}=92)$ and caregivers' $(\mathrm{n}=92)$ demographics and illness characteristics.

\begin{tabular}{|l|c|c|}
\hline Characteristics & Patients N (\%) & Caregivers N (\%) \\
\hline Age (M, SD) & $59.89(17.11)$ & $47.50(14.77)$ \\
\hline Gender & \multicolumn{2}{|c|}{} \\
\hline Female & $46(50)$ & $60(65.2)$ \\
\hline Male & $32(34.8)$ \\
\hline Marital status & $81(88.0)$ & $76(82.6)$ \\
\hline Married & $11(12)$ & $16(17.4)$ \\
\hline Single & & \\
\hline Education & $52(56.5)$ & $23(25)$ \\
\hline Literate & $32(34.8)$ & $43(46.7)$ \\
\hline Elementary & $8(8.7)$ & $26(28.3)$ \\
\hline High school & & \\
\hline Employment status & $18(19.6)$ & $31(33.7)$ \\
\hline Employed & $74(80.4)$ & $61(66.3)$ \\
\hline Unemployed & $5.71(5.17)$ & \\
\hline Illness duration (M, SD) & & \\
\hline NYHA & $26(28.3)$ & \\
\hline II & $52(56.5)$ & \\
\hline III & $14(15.2)$ & \\
\hline IV & $36.36(12.03)$ & \\
\hline Ejection Fraction (M, SD) &
\end{tabular}

Table 2. BMCS, BDCS, BSMCS (with subscales) and Zarit Burden Scale (N=92) scores.

\begin{tabular}{|l|c|c|}
\hline Scale (Number of Questions) & $\begin{array}{c}\text { Mean Score/ } \\
\text { Standard Deviation }\end{array}$ & Min-Max \\
\hline Scale of BMCS (12) & $11.97 \pm 4.27$ & $5-22$ \\
\hline Subscale of benefit (5) & $14.80 \pm 4.48$ & $7-28$ \\
\hline Subscale of barrier (7) & \multicolumn{2}{|l|}{} \\
\hline Scale of BDCS (12) & $16.14 \pm 3.45$ & $11-28$ \\
\hline Subscale of benefit (7) & $15.42 \pm 4.15$ & $5-24$ \\
\hline Subscale of barrier (5) & $18.01 \pm 5.21$ & $6-30$ \\
\hline Scale of BSMCS (18) & $31.18 \pm 7.57$ & $12-51$ \\
\hline Subscale of benefit (6) & $40.90 \pm 14.55$ & $11-71$ \\
\hline Subscale of barrier (12) & \\
\hline Zarit burden scale (22) &
\end{tabular}

\section{The Relationships of the BMCS, BDCS, and BSMCS subscale scores with the ZBI score}

The relationships between the total ZBI score and subscale scores for the BMCS, BDCS and BSMCS are showed in Table 3. We determinate a negative correlation between the total ZBI score and BMCS barrier subscale score $(\mathrm{r}=-0.449, \mathrm{P}<0.001)$. Moreover, we determinate a positive correlation between total ZBI scores and the BMCS benefit, BDCS benefit, and BSMCS benefit subscale scores ( $\mathrm{r}=0.434, \mathrm{P}<0.001$; $\mathrm{r}=0.295, \mathrm{P}=0.004$; and $\mathrm{r}=0.393, \mathrm{P}<0.001)$.

\section{Discussion}

In this study, we aimed to analyze the relationship of caregiver burden with compliance and belief in patients with heart failure and found that the mean age, EF values and gender rates were similar to those of other studies [8,17-20]. The majority of caregivers were women and they were usually either spouses or daughters of the patients. These findings were also similar to those from a study conducted by Chung [17]. Although it is experienced throughout the world, household work and care services are expected to be handled by women in the context of gender and gender-based division of labor. As observed in this study, caregiving also mostly falls to women in Turkish society [21]. A significant portion of caregivers were married and did not work for any job. In a study conducted by Trivedi et al. [18], it was stated that caregivers who did not work or go to school were more effective, although care would also be received from unmarried family members and friends.

\section{BMCS, BDCS, and BSMCS scores}

The patient subscale scores indicate that the patients have a moderate level of disease beliefs and compliance. In a study conducted by Alosco et al. [9], adherence to treatment was evaluated through keeping doctor appointments, taking medication, and smoking and alcohol consumption. Of the patients, $31.5 \%$ were non-adherent to diet, while $49.0 \%$ were non-adherent to exercise. In studies by Riegel, Smith, Alosco et al. $[8,22,23]$ similar findings were reported. The results of this study are also in line with the literature. Furthermore, this study revealed that the ages of the patients were inversely proportional with the level of barriers to beliefs in self-monitoring and medication compliance and that age was directly associated with perceived benefits. Thus, it could be argued that as the patient age, they increase their experience with the disease and could manage the disease better. This argument is supported by the fact that as the stage of heart failure classification increased, the perceived benefits in the beliefs regarding self-monitoring also increased. Although the level of sleep and social activity were not assessed in this study, the studies conducted by Bennett et al. and Naughton $[8,24]$ showed that sleep disorders and social activity limitations were the major barriers to treatment adherence.

In studies conducted with cardiac patients, the level of adherence to salt restriction was low [8,25-27]. The compliance of patients increases only when the rate of hospitalization is reduced. Patients are informed

Table 3. Relationships of the BMCS, BDCS, and BSMCS subscales scores with the Zarit Burden Scale score.

\begin{tabular}{|c|c|c|c|c|c|c|c|}
\hline & & $\begin{array}{l}\text { BMCS Subscale of } \\
\text { Benefit Score }\end{array}$ & $\begin{array}{c}\text { BMCS } \\
\text { Subscale } \\
\text { of Barrier Score }\end{array}$ & $\begin{array}{c}\text { BDCS } \\
\text { Subscale } \\
\text { of Benefit Score }\end{array}$ & $\begin{array}{c}\text { BDCS } \\
\text { Subscale } \\
\text { of Barrier Score }\end{array}$ & $\begin{array}{c}\text { BSMCS } \\
\text { Subscale of Benefit } \\
\text { Score }\end{array}$ & $\begin{array}{c}\text { BSMCS } \\
\text { Subscale } \\
\text { of Barrier Score }\end{array}$ \\
\hline $\begin{array}{l}\text { ZaritBurden } \\
\text { Scale Total Score }\end{array}$ & $\begin{array}{l}\mathrm{r} \\
\mathrm{P} \\
\mathrm{n}\end{array}$ & $\begin{array}{c}0.434 \\
<0.001 \\
92\end{array}$ & $\begin{array}{c}-0.449 \\
<0.001 \\
92\end{array}$ & $\begin{array}{c}0.295 \\
0.004 \\
92\end{array}$ & $\begin{array}{c}0.106 \\
0.314 \\
92\end{array}$ & $\begin{array}{c}0.393 \\
<0.001 \\
92\end{array}$ & $\begin{array}{r}-0.080 \\
0.448 \\
92\end{array}$ \\
\hline
\end{tabular}


about the benefits of salt restriction; however, the change in the taste of food due to salt restriction is reported to be the most common barrier to compliance [8]. As for this study, the perceived benefits of single patients regarding dietary compliance were found to be higher than that of married patients. This result suggests that dietary control could be managed better when patients are alone.

\section{Zarit Burden Interview}

In this study, the burden of caregivers was found to be higher than that found in other studies conducted with HF patients $[18,19]$. In a study conducted by Trivedi et al. [18], the mean ZBI value was $22.4 \pm 15.4$, and caregiver burden was found to be correlated with the functional limitations of the patient. Malik et al. [19] reported that the mean value of caregiver burden was 22 , and $19 \%$ of caregivers stated that they experienced a high level of burden. Harding, Garlo, Chung and McLaughlin et al. [17,28-30] also reported similar findings. In other studies, caregiver burden was found to be related to the caregiver's levels of anxiety and depression, low quality of life, quality of sleep, age and friend or family status [17-19]. It was stated that caregiver burden was not directly related to the patient's diagnosis. The fact that the burden of caregivers who tend to HF patients in Turkey is higher than that of studies in other countries could be a result of the differences in socio-cultural characteristics, level of development, individual support or the structure of health services.

This study revealed that as the number of caregiving years increased, the burden of caregivers also increased. Caregiver burden may be experienced more heavily due to various reasons, such as an increase in the physical limitations of the patient, the amount and duration of care provision, the impact on living spaces and the disruption of interpersonal relationships $[17,19]$.

\section{The Relationships of the BMCS, BDCS, and BSMCS subscale scores with the ZBI score}

In this study, as the caregiver burden increased, the patients' perceived benefits of beliefs regarding medication and dietary compliance and self-monitoring increased, while their perceived barriers to medication compliance decreased. This finding indicates that the increase in caregiver burden has a positive impact on patient care.

In studies conducted with cardiac patients, treatment adherence increased with social support, the recommendation of affordable and convenient treatment, and positive relationships of patients with their clinicians [31-33], while adherence decreased as depressive symptoms decreased [34]. In line with the literature, it could be said that the increase in caregiver experience, therefore burden has a positive impact on patients resulting in an increase in their disease compliance. At first glance, the caregiver with a high level of burden does not seem to manage the disease well. The contrary result obtained in this study is thought to make a new contribution to the literature.

The limitations of this study are that the sample was small and that the research was conducted at a single hospital. The study results can only be generalized to the sample. The patients were not classified according to the presence of additional diseases.

As a result, it was determined that the patients of caregivers with a high level of burden had higher perceived benefits of medication and dietary compliance and self-monitoring, while their perceived barriers to medication compliance were low. Therefore, it could be argued that the higher the burden of caregivers, the higher the disease compliance of patients $[17,20,35]$.It would be essential to conduct repetitive studies with larger populations to analyze the relationship between caregiver burden and disease compliance in more detail.

\section{Source of funding}

This is a self-funded study. The authors are grateful to the participants who participated in this study.

\section{References}

1. Değertekin M, Erol C, Ergene O, Tokgözoğlu L, Aksoy M, et al. (2012) Heart failure prevalence and predictors in Turkey: HAPPY study. Turk Kardiyol Dern Ars 40: 298308. [Crossref]

2. Yancy CW, Jessup M, Bozkurt B, Butler J, Casey DE Jr, et al. (2013) ACCF/AHA Practice Guideline . ACCF/AHA guideline for the management of heart failure: a report of the American College of Cardiology Foundation/American Heart Association Task Force on practice guidelines. Circulation 128: 240-327. [Crossref]

3. AHA (2016) Help For Heart Failure Caregivers. http://www.heart.org/HEARTORG/ Conditions/HeartFailure/LivingWithHeartFailureAndAdvancedHF/Help-For-HeartFailure.

4. Wingham J, Frost J, Britten N, Jolly K, Greaves C, et al. (2015) Needs of caregivers in heart failure management: A qualitative study. Chronic Illn 11:304-319. [Crossref]

5. Gusdal AK, Josefsson K, Adolfsson ET, Martin L (2016) Informal caregivers experiences and needs when caring for a relative with heart failure an interview study. $J$ Cardiovasc Nurs 31: E1-E8. [Crossref]

6. Kang X, Li Z, Nolan MT (2011) Informal caregivers' experiences of caring for patient with chronic heart failure: systematic review and meta-synthesis of qualitative studies. J Cardiovasc Nurs 26: 386-94. [Crossref]

7. Pressler SJ, Gradus-Pizlo I, Chubinski SD, Smith G, Wheeler S, et al. (2009) Family caregiver outcomes in heart failure. Am J Crit Care 18: 149-159. [Crossref]

8. Bennett SJ, Lane KA, Welch J, Perkins SM, Brater DC, et al. (2005) Medication and dietary compliance beliefs in heart failure. West J Nurs Res 27: 977-993. [Crossref]

9. van der Wal MH, Jaarsma T, Moser DK, Veeger NJ, van Gilst WH, et al. (2006) Compliance in heart failure patients: the importance of knowledge and beliefs. Eur Heart J 27: 434-440. [Crossref]

10. Alosco ML, Spitznagel MB, Cohen R, Sweet LH, Josephson R, et al. (2014) Better adherence to treatment recommendations in heart failure predicts improved cognitive function at a one-year follow up. J Clin Exp Neuropsychol 36: 956-966. [Crossref]

11. Alosco ML, Spitznagel MB, van Dulmen M, Raz N, Cohen R, et al. (2012) Cognitive Function and Treatment Adherence in Older Adults with Heart Failure. Psychosom Med 74: 965-973. [Crossref]

12. Bennett SJ, Milgrom LB, Champion V, Huster GA (1997) Beliefs about medication and dietary compliance in people with heart failure: an instrument development study. Heart Lung 26: 273-279. [Crossref]

13. Bennett SJ, Perkins SM, Lane KA, Forthofer MA, Brater DC, et al. (2001) Reliability and validity of the compliance belief scales among patients with heart failure. Heart Lung 30: 177-185. [Crossref]

14. Oğuz S, Enç N, Yiğit Z (2010) Adaptation of the compliance and belief scales to Turkish for patients with chronic heart failure. Arch Turk Soc Cardiol 38: 480-485. [Crossref]

15. Zarit SH, Reever KE, Bach-Peterson J (1980) Relatives of the impaired elderly: correlates of feelings of burden. Gerontologist 20: 649-655. [Crossref]

16. Inci FH, Erdem M (2008) Validity and reliability of the burden interview and its adaptation to turkish. Atatürk University School of Nursing Journal 11: 85-95.

17. Chung ML, Pressler SJ, Dunbar SB, Lennie TA, Moser DK (2010) Predictors of depressive symptoms in caregivers of patients with heart failure. J Cardiovasc Nurs 25: 411-419. [Crossref]

18. Trivedi RB, Piette J, Fihn SD, Edelman D (2012) Examining the interrelatedness of patient and spousal stress in heart failure, conceptual model and pilot data. J Cardiovasc Nurs 27: 24-32. [Crossref]

19. Malik FA, Gysels M, Higginson IJ (2013) Living with breathlessness: A survey of caregivers of breathless patients with lung cancer or heart failure. Palliat Med 27: 647656. [Crossref]

20. Hirano A, Umegaki H, Suzuki Y, Hayashi T, Kuzuya M (2015) Effects of leisure 
activities at home on perceived care burden and the endocrine system of caregivers of dementia patients: a randomized controlled study. Int Psychogeriatr 28: 261-268. [Crossref]

21. Özer S (2010) Family/Caregiver Burden In Heart Failure. Turk Soc Cardiol Turkish Journal of Cardiovascular Nursing 1: 3-7.

22. Riegel B, Moser DK, Anker SD, Appel LJ, Dunbar SB, et al. (2009) American Heart Association interdisciplinary council on quality of care and outcomes research. state of the science: promoting self-care in persons with heart failure. A scientific statement from the American Heart Association. Circulation 120: 1141-1163. [Crossref]

23. Smith H, Hankins M, Hodson A, George C (2010) Measuring the adherence to medication of elderly patients with heart failure: Is there a gold standard? Int J Cardiol 145: 122-123. [Crossref]

24. Naughton MT (2003) Sleep disorders in patients with congestive heart failure. Curr Opin Pulm Med 9: 453-458. [Crossref]

25. Bennett SJ, Cordes DK, Westmoreland G, Castro R, Donnelly E (2000) Self-care strategies for symptom management in patients with chronic heart failure. Nurs Res 49 : 139-145. [Crossref]

26. Evangelista L, Dracup K, Doering L (2000) A closer look at compliance research in heart failure patients in the last decade. Prog Cardiovasc Nurs 15: 97-103. [Crossref]

27. Evangelista LS, Berg J, Dracup K (2001) Relationship between psychosocial variables and compliance in patients with heart failure. Heart Lung 30: 294-301. [Crossref]
28. Harding R, Higginson IJ, Leam C, et al. (2004) Evaluation of a short-term group intervention for informal cares of patients attending a home palliative care service. $J$ Pain Symptom Manage 27(5): 396-408. [Crossref]

29. Garlo K, O’Leary JR, Van Ness PH, Fried TR (2010) Burden in caregivers of older adults with advanced illness. J Am Geriatr Soc 58: 2315-2322. [Crossref]

30. McLaughlin D, Hasson F, Kernohan WG, Waldron M, McLaughlin M, et al. (2011) Living and coping with Parkinson's disease: perceptions of informal carers. Palliat Med 25: 177-182. [Crossref]

31. Adams AS, Soumerai SB, Lomas J, Ross-Degnan D (1999) Evidence of self-report bias in assessing adherence to guidelines. Int J Qual Health Care 11: 187-192. [Crossref]

32. Aggarwal B, Liao M, Allegrante JP, Mosca L (2010) Low social support is associated with nonadherence to diet at 1 year in the Family Intervention Trial for Heart Health (FIT Heart). J Nutr Educ Behav 42: 380-388. [Crossref]

33. Murray MD, Morrow DG, Weiner M, Clark DO, Tu W, et al. (2004) A conceptual framework to study medication adherence in older adults. Am J Geriatr Pharmacother 2 : 36-43. [Crossref]

34. McGrady A, McGinnis R, Badenhop D, Bentle M, Rajput M (2009) Effects of depression and anxiety on adherence to cardiac rehabilitation. $J$ Cardiopulm Rehabil Prev 29: 358-364. [Crossref]

35. Saunders MM (2010) Working and caregiving a comparison of employed and unemployed caregivers of older heart failure patients. Holist Nurs Pract 24: 16-22. [Crossref]

Copyright: (C2017 Sevinc S. This is an open-access article distributed under the terms of the Creative Commons Attribution License, which permits unrestricted use, distribution, and reproduction in any medium, provided the original author and source are credited. 